\title{
Herutusajan väkirehun nostonopeuden ja väkirehun koostumuksen vaiku- tukset maitotuotokseen ja rehun syöntiin alkulypsykaudesta
}

\author{
Päivi Mäntysaari ${ }^{1}$, Hannele Khalili ${ }^{1}$, Juha Sariola ${ }^{1}$, Reima Kangasniemi ${ }^{1}$ ja Merja Holma ${ }^{2}$
}

${ }^{1}$ MTT Kotieläintuotannon tutkimus, 31600 Jokioinen, etunimi.sukunimi@mtt.fi

${ }^{2}$ Rehuraisio Oy, PL 101, 21201Raisio, merja.holma@ raisiogroup.com

\section{Tiivistelmä}

Hyvätuottoisen lypsylehmän tuotannon ja terveyden ylläpitämiseksi on tärkeää, että rehun syönti lisääntyy nopeasti poikimisen jälkeen ja pysyy vakaana lypsykauden edetessä. Mikäli syönninkehitys poikimisen jälkeen on hidasta ja lehmä joutuu mobilisoimaan kudoksistaan, niin riski aineenvaihduntasairauksiin kasvaa. Tämän tutkimuksen tarkoituksena on selvittää väkirehun koostumuksen ja herutusnopeuden vaikutusta lehmien kolmen ensimmäisen lypsykuukauden ajan rehun syöntiin, maidontuotantoon ja maidon koostumukseen.

Koe suoritettiin MTT:n Minkiön tutkimuspihatossa Jokioisilla. Kokeessa oli kaikkiaan 64 Ay lehmää. Lehmät tulivat kokeeseen poikimisen jälkeen ja olivat kokeessa ensimmäiset 100 laktaatiopäivää. Koe järjestettiin erillisruokintana niin, että puolet koelehmistä sai tärkkelyspitoista väkirehua (TR) ja puolet kuitupitoista väkirehua (KR). Ennen poikimista väkirehuannos oli ensikoilla $3 \mathrm{~kg} / \mathrm{pv}$ ja vanhemmilla lehmillä $4 \mathrm{~kg} / \mathrm{pv}$. Poikimisen jälkeen väkirehuannos nostettiin tavoiteannokseen 12 päivässä (NH=nopea herutus) tai 24 päivässä (HH=hidas herutus). Lypsykauden tavoiteannos oli ensikoilla $13,5 \mathrm{~kg} / \mathrm{pv}$ ja vanhemmilla lehmillä $17,0 \mathrm{~kg} / \mathrm{pv}$. Herutuksen jälkeen väkirehuannos pysyi samana koko loppukokeen ajan. Nurmisäilörehua lehmät saivat vapaasti. Väkirehut olivat Rehuraisio Oyn valmistamia täysrehuja. KR-rehu sisälsi ohraa, rypsirouhetta, rypsipuristetta, melassileikettä, maissirankkia, vehnäsiirappia, soijarouhetta, leseseosta ja kivennäisiä sekä vitamiineja. TR-rehu sisälsi ohraa, vehnää, soijarouhetta, rypsirouhetta, vehnäsiirappia ja kivennäisiä sekä vitamiineja. Rehun energiapitoisuus oli TR-rehussa 1,10 ja KR-rehussa 1,07 ry/kg ka. Raakavalkuaista oli molemmissa rehuissa yhtä paljon (205 ja 203 g/kg ka). KR-rehussa oli tärkkelystä vähemmän (258 vs. 421 g/kg ka) ja NDF-kuitua enemmän (251 vs. $167 \mathrm{~g} / \mathrm{kg} \mathrm{ka)} \mathrm{kuin} \mathrm{TR-rehussa.} \mathrm{Säilörehun} \mathrm{D-arvo} \mathrm{oli} \mathrm{kokeen} \mathrm{aikana}$ keskimäärin 71,1 ja raakavalkuaispitoisuus $159 \mathrm{~g} / \mathrm{kg}$ kuiva-ainetta.

Kuitupitoinen väkirehu lisäsi väkirehun $(12,3$ vs. $11,7 \mathrm{~kg} \mathrm{ka} / \mathrm{pv} ; \mathrm{P}<0,001)$ ja vähensi säilörehun $(8,5$ vs. $9,2 \mathrm{~kg} \mathrm{ka} / \mathrm{pv} ; \mathrm{P}<0,05)$ syöntiä verrattuna tärkkelyspitoiseen väkirehuun. Kokonaissyöntiin ja energian tai valkuaisen saantiin väkirehun koostumus ei kuitenkaan vaikuttanut. Maitotuotokset olivat kuitupitoista väkirehua saaneilla lehmillä korkeammat $(33,0$ vs. $31,1 \mathrm{~kg} / \mathrm{pv} ; \mathrm{P}<0,05)$ kuin tärkkelyspitoista väkirehua saaneilla. Maidon valkuaispitoisuus oli korkeampi TR-rehulla kuin KR-rehulla (35,2 vs. 34,2 g/kg; P<0,05), rasvapitoisuuteen ei väkirehu vaikuttanut. Energian hyväksikäyttö oli kuitupitoisella rehulla ruokittaessa parempi kuin tärkkelyspitoisella rehulla ruokittaessa $(\mathrm{P}<0,05)$.

Nopeasti herutettaessa (tavoiteväkirehulisäys 800-1000 g/pv) lehmät eivät pystyneet lisäämään herutuskaudella tärkkelyspitoisen väkirehun syöntiä yhtä nopeasti kuin kuitupitoisen väkirehun syöntiä. Sen sijaan hitaalla herutuksella (tavoiteväkirehulisäys $450-550 \mathrm{~g} / \mathrm{pv}$ ) ei väkirehujen välillä ollut eroa väkirehun syönnin kehityksessä herutuskaudella. Koko kokeen aikaiseen kuiva-aineen syönnin kehitykseen ei herutusnopeudella ollut vaikutusta. Energiakorjattu maitotuotos oli korkeampi hitaalla herutuksella kuin nopealla herutuksella $(34,1$ vs. $32,0 \mathrm{~kg} / \mathrm{pv} ; \mathrm{P}<0,05)$, maidon pitoisuuksissa ei ollut eroa.

Koetulokset osoittivat, että runsaalla väkirehuruokinnalla (dieetissä väkirehua 55-65\%) lypsylehmät hyötyivät kuitupitoisen väkirehun syötöstä. Kuitupitoinen väkirehu lisäsi maitotuotoksia ja paransi energian hyväksikäyttöä. Nopeasti herutettaessa väkirehun syönti kehittyi nopeammin kuitupitoisella väkirehulla. Kokonaiskuiva-aineen syönnin kehitykseen herutusnopeus ei vaikuttanut. Hitaasti herutetuilla lehmillä oli koekauden (100 pv) keskimääräinen energiakorjattu maitotuotos korkeampi kuin nopeasti herutetuilla lehmillä. Erityisesti tärkkelyspitoisella rehulla nopea herutus laski koekauden keskimääräistä energiakorjattua maitotuotosta ja energian sekä valkuaisen hyväksikäyttöä.

Avainsanat: Lypsylehmä, maidontuotanto, väkirehu, herutus 


\section{Tausta}

Hyvätuottoisen lypsylehmän tuotannon ja terveyden ylläpitämiseksi on tärkeää, että rehun syönti lisääntyy nopeasti poikimisen jälkeen ja pysyy vakaana lypsykauden edetessä. Mikäli syönninkehitys poikimisen jälkeen on hidasta ja lehmä joutuu mobilisoimaan kudoksistaan, niin riski aineenvaihduntasairauksiin kasvaa. Syönnin kehitykseen vaikuttaa herutusnopeus, mutta myös väkirehun koostumus. Väkirehut, jotka sisältävät elintarviketeollisuuden sivutuotteita, sisältävät enemmän sulavaa kuitua ja vähemmän tärkkelystä kuin viljapohjaiset väkirehut. Kuitupitoiset sivutuotteet fermentoituvat pötsissä hitaammin kuin viljan tärkkelys, joten pötsin $\mathrm{pH}$ ei laske kuitupitoisilla väkirehuilla yhtä alas kuin pelkästään viljaa käytettäessä (Huhtanen, 1992). Tällä on positiivinen vaikutus pötsin toiminnalle ja karkearehun sulavuudelle (Shriver ym., 1986) sekä syönnille (Ala-Seppälä ym., 1988; Huhtanen ym., 1995). Toisaalta suuria rehumääriä syövillä lypsylehmillä on rehun viipymisaika pötsissä lyhyt, jolloin runsaasti kuitupitoista väkirehua sisältävän dieetin sulavuus voi jäädä alhaiseksi verrattuna tärkkelyspitoisempaa väkirehua sisältävään dieettiin (Huhtanen ym. 1988). Tämän tutkimuksen tarkoituksena on selvittää herutuksen pituuden ja väkirehun koostumuksen vaikutusta lehmien kolmen ensimmäisen lypsykuukauden ajan rehun syöntiin, maidontuotantoon ja maidon koostumukseen.

\section{Aineisto ja menetelmät}

Koe suoritettiin MTT:n Minkiön tutkimuspihatossa Jokioisilla. Kokeessa oli kaikkiaan 64 Ay lehmää, joista 21 oli ensikoita ja 43 useamman kerran poikineita. Lehmät tulivat kokeeseen poikimisen jälkeen ja olivat kokeessa ensimmäiset 100 laktaatiopäivää. Koefaktoreina olivat väkirehun koostumus ja herutusnopeus. Koe järjestettiin erillisruokintana niin, että puolet koelehmistä sai tärkkelyspitoista väkirehua (TR) ja puolet kuitupitoista väkirehua (KR). Väkirehu jaettiin väkirehuautomaatista. Kaikki lehmät tunnutettiin saman ohjeen mukaan; väkirehumäärä (TR tai KR) nostettiin 3 viikossa ensikoilla 3 ja vanhemmilla lehmillä 4 kilogrammaan päivässä. Poikimisen jälkeen väkirehuannos nostettiin tavoiteannokseen 12 päivässä (NH=nopea herutus) tai 24 päivässä (HH=hidas herutus). Lypsykauden tavoiteannos oli ensikoilla $13,5 \mathrm{~kg} / \mathrm{pv}$ ja vanhemmilla lehmillä $17,0 \mathrm{~kg} / \mathrm{pv}$, joten väkirehuannoksen lisäys oli vanhemmilla lehmillä nopealla herutuksella $1,08 \mathrm{~kg} / \mathrm{pv}$ ja hitaalla herutuksella $0,542 \mathrm{~kg} / \mathrm{pv}$. Ensikoilla vastaavat luvut olivat $0,875 \mathrm{ja} 0,437 \mathrm{~kg} / \mathrm{pv}$. Herutuksen jälkeen väkirehuannos pysyi samana koko loppukokeen ajan. Nurmisäilörehua lehmät saivat vapaasti.

Väkirehut olivat Rehuraisio Oyn valmistamia täysrehuja. KR-rehu sisälsi (g/kg) ohraa (350), rypsirouhetta (100), rypsipuristetta (100), melassileikettä (200), maissirankkia (100), vehnäsiirappia (50), soijarouhetta (37), leseseosta (32) ja kivennäisiä sekä vitamiineja (31). TR-rehu sisälsi (g/kg) ohraa (350), vehnää (350), soijarouhetta (160), rypsirouhetta (57), vehnäsiirappia (50) ja kivennäisiä sekä vitamiineja (33). Väkirehujen valkuaistavoite oli 200 g/kg ka. Säilörehu oli MTT:n kesän 2004 ensimmäisen sadon nurmisäilörehua.

Lehmät lypsettiin kaksi kertaa päivässä. Maitomäärä rekisteröitiin jokaiselta lypsykerralta. Maitonäytteet otettiin kahden viikon välein. Maitonäytteistä määritettiin rasva, valkuainen ja laktoosi. Urea määritettiin joka toisen näytteenottokerran näytteistä seitsemältä lehmältä per koeruokinta. Säilörehun ja väkirehun syönti mitattiin päivittäin eläinkohtaisesti.

Säilörehusta otettiin kaksi kertaa viikossa näytteet, jotka kerättiin kahden viikon jaksonäytteiksi. Näytteistä analysoitiin pH, kuiva-aine, tuhka, raakavalkuainen, NDF, in vitro -sellulaasisulavuus ja käymislaatu. Väkirehuista otettiin keruunäytteet kerran viikossa. Keruujakson pituus oli 4 viikkoa. Väkirehunäytteistä analysoitiin kuiva-aine, tuhka, raakarasva, raakavalkuainen, raakakuitu, NDF ja tärkkelys. Lehmien elopaino rekisteröitiin läpikulkuvaa'assa jokaisen lypsyn yhteydessä. Koelehmät kuntoluokitettiin (asteikko: 1=laiha $-5=$ =hyvin lihava; Lowman ym. 1975) poikimapäivänä tai sitä seuraavana päivänä ja tämän jälkeen kahden viikon välein.

Säilörehun D-arvo määritettiin in vitro-sulavuutena sellulaasimenetelmällä ja rehujen rehuarvot laskettiin Rehutaulukoissa (MTT, 2004) esitettyjen laskentaperusteiden mukaan. Eläinkohtaisesta päivittäisestä tuotos-, syönti- ja painodatasta laskettiin viikkokeskiarvot, joita käytettiin toistohavaintoina analyyseissä. Nämä lehmäkohtaiset viikkohavainnot analysoitiin käyttäen SASin MIXED ohjelmaa. Mallissa oli mukana väkirehu (KR tai TR), herutuksen pituus (12 tai 24 pv), poikimakerta, eläin satunnaistekijänä, laktaatioviikko ja tuotostietoja analysoitaessa maito-, rasva-\%, rasvakilo-, valkuais$\%$ tai valkuaiskilojalostusindeksi syksyn 2004 arvosteluissa. Ensikon kohdalla käytettiin vanhempien 
indeksien keskiarvoa. Taulukoissa tilastolliset merkitsevyydet on ilmaistu seuraavasti: o $\mathrm{P}<0.10$; * $\mathrm{P}<0.05 ; * \mathrm{P}<0.01 ; * * * \mathrm{P}<0.001$.

\section{Tulokset ja tulosten tarkastelu}

Väkirehut olivat koostumukseltaan ja ravintoarvoiltaan suunnitellun mukaisia, KR-rehussa oli tärkkelystä vähemmän (258 vs. $421 \mathrm{~g} / \mathrm{kg} \mathrm{ka}$ ) ja NDF-kuitua enemmän (251 vs. $167 \mathrm{~g} / \mathrm{kg} \mathrm{ka})$ kuin TRrehussa. Raakavalkuaista oli molemmissa väkirehuissa yhtä paljon (205 ja $203 \mathrm{~g} / \mathrm{kg} \mathrm{ka})$. Säilörehun Darvo oli kokeen aikana keskimäärin 71,1 ja raakavalkuaispitoisuus $159 \mathrm{~g} / \mathrm{kg}$ kuiva-ainetta. Väkirehujen ja säilörehun kemiallinen koostumus sekä lasketut rehuarvot on annettu Taulukossa 1.

Taulukko 1. Rehujen kemiallinen koostumus ja lasketut rehuarvot.

\begin{tabular}{lccc}
\hline & Säilörehu $^{1}$ & Tärkkelysväkirehu & Kuituväkirehu \\
\hline Kuiva-aine, g/kg & & & \\
Kuiva-aineessa, g/kg & 245,8 & 871,7 & 878,1 \\
$\quad$ Tuhka & 78,0 & 59,9 & 76,6 \\
$\quad$ Raakavalkuainen & 158,7 & 204,9 & 202,9 \\
$\quad$ Raakarasva & - & 38,0 & 49,8 \\
NDF & 494,5 & 167,2 & 250,9 \\
Tärkkelys & - & 420,9 & 257,9 \\
Rehuarvot & 0,97 & 1,10 & 1,07 \\
Ry/ kg ka & 11,4 & 12,8 & 12,5 \\
ME/kg ka & 87,5 & 114,8 & 122,2 \\
OIV, g/kg ka & 9,5 & 20,4 & 9,4 \\
PVT, g/kg ka & &
\end{tabular}

Kokeenaikaiseen keskimääräiseen kuiva-ainesyöntiin ei väkirehulla tai herutuksella ollut vaikutusta. Sen sijaan väkirehun koostumus vaikutti merkitsevästi kokeenaikaiseen keskimääräiseen väkirehun syöntiin (Taulukko 2). Kuitupitoisen väkirehun syönti oli koekaudella runsaampaa kuin tärkkelyspitoisen rehun. Aikaisemmissa kokeissa on kuitupitoisen väkirehun syönti ollut joko sama (Huhtanen, 1993) tai alhaisempi (Huhtanen ym., 1988) kuin tärkkelyspitoisen väkirehun. Näissä kokeissa oli dieetin väkirehupitoisuus $35-45 \%$, kun se tässä kokeessa oli $55-65 \%$. Vaikka väkirehuannokset olivat tässä kokeessa korkeat, niin pystyivät KR-rehua saaneet lehmät kuitenkin syömään lähes täydet annokset laktaatioviikoilla 6-15 (vanhemmat $16,7 \mathrm{~kg} / \mathrm{pv}$ ja ensikot $13,3 \mathrm{~kg} / \mathrm{pv}$ ), TR-rehulla annokset jäivät alhaisemmiksi (vanhemmat $15,8 \mathrm{~kg} / \mathrm{pv}$ ja ensikot $13,1 \mathrm{~kg} / \mathrm{pv}$ ).

Nopea herutus lisäsi keskimääräistä väkirehun syöntiä koekaudella. Väkirehun, herutuksen ja lypsykauden vaiheen välinen yhdysvaikutus tuli merkitseväksi väkirehun syönnille $(\mathrm{P}<0.05)$, koska hitaasti herutettaessa lehmät söivät herutuskaudella molempia väkirehuja yhtä paljon, mutta nopealla herutuksella eivät lehmät pystyneet lisäämään TR-rehun syöntiä lypsykauden alussa samaa vauhtia kuin KR-rehun syöntiä (Kuva 1). Tulokset osoittavat, että poikimisen jälkeen 800 - $1000 \mathrm{~g}$ päivittäinen lisäys väkirehuannoksessa oli tärkkelyspitoisella väkirehulla liian paljon.

Vähemmän väkirehua syöneet TR-ryhmän lehmät söivät koekaudella enemmän säilörehua kuin KR-ryhmän lehmät $(\mathrm{P}<0,05)$. TR-ryhmällä säilörehun syönti oli keskimäärin $9,2 \mathrm{~kg} \mathrm{ka} / \mathrm{pv}$ ja KRryhmallä $8,5 \mathrm{~kg} \mathrm{ka} / \mathrm{pv}$ (Taulukko 2). Alhaisimmaksi säilörehun syönti jäi kutupitoisella väkirehulla ja nopealla herutuksella $(\mathrm{KR}+\mathrm{NH})($ Kuva 2). Herutuskaudella $\mathrm{KR}+\mathrm{NH}$ ryhmän alhaisempi säilörehun syönti on selitettävissä runsaammalla väkirehun syönnillä. Säilörehun syönti ei KR+NH-ryhmällä kuitenkaan lisääntynyt lypsykauden edetessä muiden ryhmien tasolla, vaikka erot väkirehun syönnissä tasoittuivatkin. 


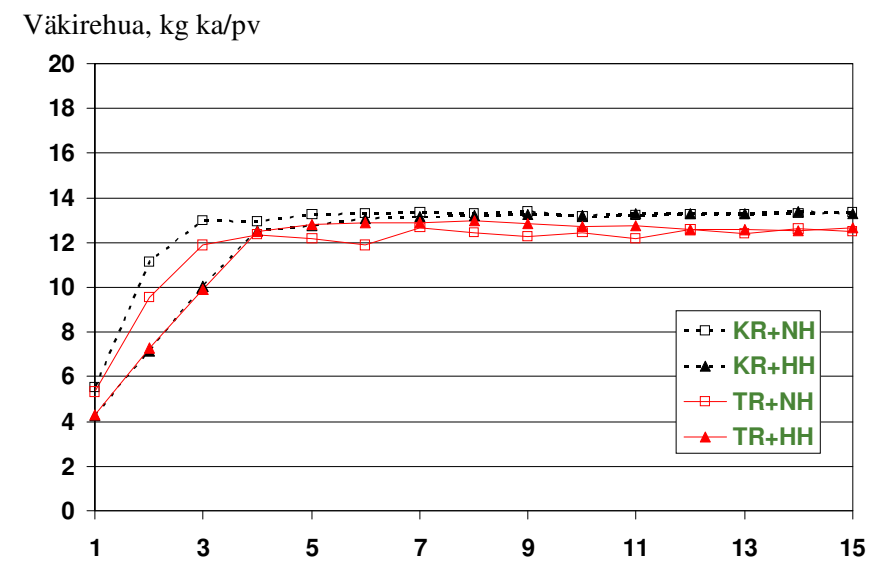

Laktaatioviikko

Kuva 1. Väkirehun syönnin kehitys koekaudella.

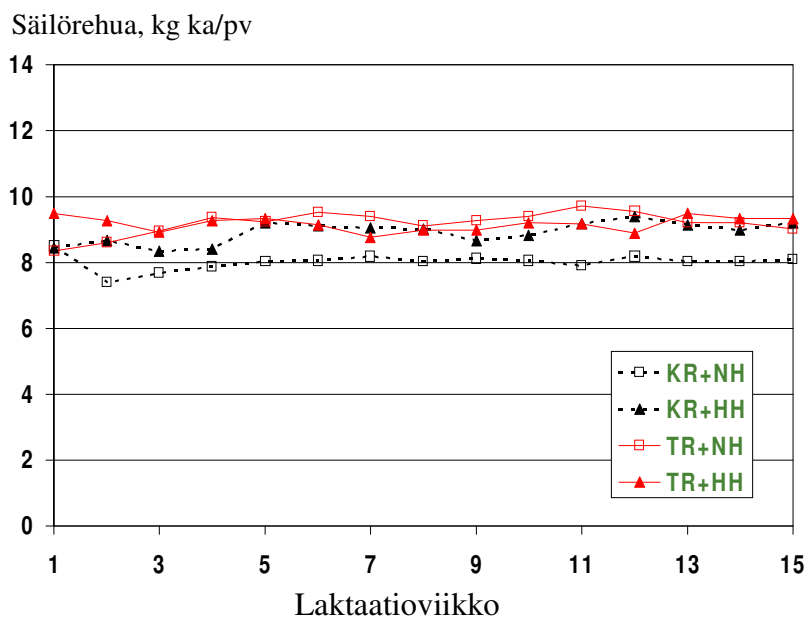

Kuva 2. Säilörehun syönninkehitys koekaudella

Keskimääräisessä energian saannissa (ry/pv) ei ryhmien välillä ollut eroa (Taulukko 2), mutta luonnollisesti herutuskaudella nopeammin herutetuilla energian saanti lisääntyi nopeammin. Myöskään raakavalkuaisen saannissa ei ryhmien välillä ollut eroa. OIV- ja raakarasvasaanti oli kuitupitoista väkirehua saaneilla suurempi kuin tärkkelyspitoista väkirehua saaneilla johtuen KR-rehun korkeammasta OIV- ja rasvapitoisuudesta. Koeasetelman mukaisesti lehmät KR-ruokinnalla saivat vähemmän tärkkelystä ja enemmän NDF-kuitua kuin TR-ruokinnalla olleet lehmät.

Kuituväkirehua saaneet lehmät lypsivät enemmän maitoa kuin tärkkelysväkirehulla ruokitut (Taulukko 2; Kuva 3). Ero väkirehujen välillä oli merkitsevä maitotuotoksissa $(\mathrm{P}<0,05)$ ja lähes merkitsevä EKM-tuotoksessa $(\mathrm{P}<0,10)$. Herutusnopeus ei vaikuttanut merkitsevästi maitotuotokseen, mutta EKM-tuotos oli merkitsevästi korkeampi hitaasti herutetuilla kuin nopeasti herutetuilla lehmillä (Taulukko 2). Herutuskaudella KR-ruokinnalla herutusnopeus ei vaikuttanut EKM-tuotoksiin, mutta TR-ruokinnalla nopeasti herutetut eivät pystyneet herumaan samaa vauhtia kuin hitaasti herutetut (vä- 
kir.*herut.*lypsyvk.; P<0,06). Lypsykauden edetessä olivat EKM-tuotokset korkeammat hitaasti herutetuilla lehmillä molemmilla ruokinnoilla.

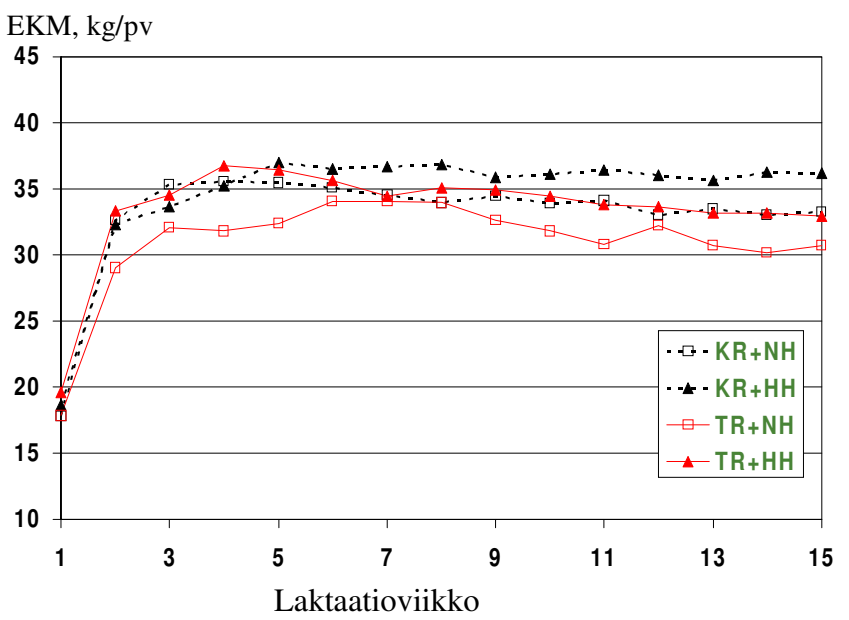

Kuva 3. Energiakorjattu maitotuotos koekaudella.

Koekauden keskimääräinen maidon rasvapitoisuus oli korkein KR+HH-ruokinnalla, ero ei kuitenkaan ollut merkitsevä. Rasvatuotos oli korkeampi KR-ruokinnalla kuin TR-ruokinnalla, mikä johtui paitsi KR-ryhmän korkeammista maitotuotoksista niin myös mainituista eroista rasvapitoisuudessa. Väkirehu ei vaikuttanut keskimääräisiin valkuaistuotoksiin, sillä maidon valkuaispitoisuus oli korkeampi TR-ruokinnalla kuin KR-ruokinnalla, mikä näin kompensoi alhaisemmat maitotuotokset TRruokinnalla. Hidas herutus lisäsi jonkin verran valkuais- ja rasvatuotoksia johtuen korkeammista maitotuotoksista, sillä maidon rasva ja valkuaispitoisuuksiin ei herutusnopeus vaikuttanut.

Koska laskennallisessa energian saannissa koeryhmien välillä ei ollut eroa, mutta tuotokset olivat korkeammat kuiturehulla, oli energian hyväksikäyttö (EKM/ry) parempi kuitupitoisella väkirehulla ruokittaessa. Myös hidas herutus paransi energian hyväksikäyttöä. Valkuaisen hyväksikäytössä (maitovalkuainen/rehuvalkuainen) väkirehun ja herutuksen välinen yhdysvaikutus tuli merkitseväksi, mikä johtui siitä, että KR-ruokinnalla ei herutuksen nopeudella ollut vaikutusta, mutta TR-ruokinnalla oli valkuaisen hyväksikäyttö parempi hitaalla herutuksella. Keskimääräinen valkuaisen hyväksikäyttö koko aineistosta laskettuna oli 0,289 . Väkirehulla tai herutusnopeudella ei ollut vaikutusta lehmien elopainon tai kunnon kehitykseen koekaudella. Kaikilla ryhmillä oli kunto kokeen alussa hieman yli 3 ja kokeen lopussa noin 2,8 .

\section{Johtopäätökset}

Koetulokset osoittivat, että runsaalla väkirehuruokinnalla (dieetissä väkirehua 55-65\%) lypsylehmät hyötyivät kuitupitoisen väkirehun syötöstä. Kuitupitoinen väkirehu lisäsi maitotuotoksia ja paransi energian hyväksikäyttöä. Nopeasti herutettaessa (tavoiteväkirehulisäys 800-1000 g/pv) lehmät eivät pystyneet lisäämään herutuskaudella tärkkelyspitoisen väkirehun syöntiä yhtä nopeasti kuin kuitupitoisen väkirehun syöntiä. Sen sijaan hitaalla herutuksella (tavoiteväkirehulisäys 450-550 g/pv) ei väkirehujen välillä ollut eroa herutuskauden väkirehun syönnin kehityksessä. Koko kokeen aikaiseen kuiva-ainesyönnin kehitykseen ei herutusnopeudella ollut vaikutusta. Hitaasti herutetuilla lehmillä olivat EKM-tuotokset korkeammat kuin nopeasti herutetuilla lehmillä. Erityisesti tärkkelyspitoisella rehulla nopea herutus laski koekauden (100 pv) keskimääräistä EKM-tuotosta ja energian sekä valkuaisen hyväksikäyttöä. 


\section{Kirjallisuus}

Ala-Seppälä H., Huhtanen, P. \& Näsi, M. 1988. Silage intake and milk production in cows given barley or barley fibre with or without dried distillers solubles. J. Agric. Sci. Finl. 60:737-733.

Huhtanen, P., Jakkola, S., Saarisalo, E. 1995. The effects of concentrate energy source on milk production of dairy cows given a grass silage-based diet. Animal Sci. 60:31-40.

Huhtanen, P. 1992. The effects of barley vs. barley fibre with or without distiller's solubles on site and extent of nutrient digestion in cattle fed grass-silage-based diet. Animal Feed Sci. Techn. 36:319337.

Huhtanen, P., Ala-Seppälä, H. \& Näsi, M. 1988. Response of silage intake and milk production to replacement of barley by barley fibre derived from integrated starch-ethanol process. J. Agric. Sci. Finl. 60:711-721.

Lowman, B. G., Scott, N. A. \& Somerville, S. H. 1976. Condition scoring of cattle. In: The East of Scotland Coll. Agric. Bull. No. 6.

MTT, 2004. Rehutaulukot ja ruokintasuositukset 2004 märehtijät - siat - siipikarja - turkiseläimet hevoset. MTT:n selvityksiä 86, http://www.mtt.fi/mtts/pdf/mtts86.pdf

Shriver, B.J., Hoover, W.H., Sargent, R.J., Jr. \& Thayne, W.V. 1986. Fermentation of high concentrate diet as affected by ruminal pH and digesta flow. J. Dairy Sci. 69:413-419. 
Taulukko 2. Koelehmien keskimääräiset tuotokset ja syönnit eri ruokinnoilla koekaudella.

\begin{tabular}{|c|c|c|c|c|c|c|c|c|c|}
\hline & \multicolumn{4}{|c|}{ Koeryhmä } & & \multicolumn{4}{|c|}{ Tilastollinen merkitsevyys $(\mathrm{P}<)^{1}$} \\
\hline & $\begin{array}{l}\text { Kuiturehu } \\
\text { + nopea } \\
\text { herutus }\end{array}$ & $\begin{array}{l}\text { Kuiturehu } \\
\text { + hidas he- } \\
\text { rutus }\end{array}$ & $\begin{array}{l}\text { Tärkkelysre- } \\
\text { hu + nopea } \\
\text { herutus }\end{array}$ & $\begin{array}{l}\text { Tärkkelys- } \\
\text { rehu+ hidas } \\
\text { herutus }\end{array}$ & SEM $^{2}$ & Väkirehu & $\begin{array}{l}\text { Herutus- } \\
\text { nopeus }\end{array}$ & $\begin{array}{l}\text { Väkirehu* } \\
\text { Herutus- } \\
\text { nopeus }\end{array}$ & $\begin{array}{l}\text { Väkirehu* } \\
\text { Herutus- } \\
\text { nopeus* } \\
\text { laktaa- } \\
\text { tioviikko }\end{array}$ \\
\hline \multicolumn{10}{|l|}{ Syönti ja ravintoaineiden saanti } \\
\hline Kuiva-aine, $\mathrm{kg} / \mathrm{pv}$ & 20,6 & 20,9 & 20,9 & 20,8 & 0,29 & & & & \\
\hline Väkirehu, kg ka/pv & 12,6 & 12,0 & 11,7 & 11,6 & 0,08 & $* * *$ & $* * *$ & $* * *$ & $*$ \\
\hline Säilörehu, kg ka/pv & 8,0 & 8,9 & 9,2 & 9,2 & 0,32 & $*$ & & & $*$ \\
\hline $\mathrm{Ry} / \mathrm{pv}$ & 21,3 & 21,5 & 21,8 & 21,7 & 0,27 & & & & \\
\hline Raakavalkuainen, $\mathrm{kg} / \mathrm{pv}$ & 3,79 & 3,83 & 3,81 & 3,78 & 0,048 & & & & \\
\hline Raakarasva, kg/pv & 0,95 & 0,96 & 0,81 & 0,81 & 0,011 & $* * *$ & & & \\
\hline $\mathrm{OIV}, \mathrm{kg} / \mathrm{pv}$ & 2,24 & 2,24 & 2,14 & 2,13 & 0,024 & $* * *$ & & & \\
\hline Tärkkelys, kg/pv & 3,25 & 3,07 & 4,97 & 4,92 & 0,032 & $* * *$ & $* * *$ & $*$ & \\
\hline $\mathrm{NDF}, \mathrm{kg} / \mathrm{pv}$ & 7,17 & 7,41 & 6,47 & 6,47 & 0,152 & $* * *$ & & & \\
\hline \multicolumn{10}{|l|}{ Maitotuotos ja pitoisuudet } \\
\hline Maito, kg/pv & 32,9 & 33,1 & 29,8 & 32,4 & 0,91 & $*$ & & & \\
\hline $\mathrm{EKM}, \mathrm{kg} / \mathrm{pv}$ & 33,0 & 34,6 & 30,9 & 33,5 & 0,96 & o & $*$ & & $\mathrm{o}$ \\
\hline Rasva, kg/pv & 1,28 & 1,41 & 1,22 & 1,29 & 0,046 & o & $*$ & & $* *$ \\
\hline Valkuainen, $\mathrm{kg} / \mathrm{pv}$ & 1,11 & 1,13 & 1,04 & 1,14 & 0,027 & & $*$ & & \\
\hline Rasva, g/kg & 39,4 & 42,7 & 40,8 & 40,9 & 1,30 & & & & $* *$ \\
\hline Valkuainen, g/kg & 34,0 & 34,3 & 35,0 & 35,8 & 0,52 & $*$ & & & \\
\hline Urea, mg/100ml & 24,1 & 24,7 & 27,9 & 26,0 & 1,36 & o & & & \\
\hline \multicolumn{10}{|l|}{ Hyväksikäyttö } \\
\hline $\mathrm{EKM} / \mathrm{ry}$ & 1,54 & 1,61 & 1,40 & 1,53 & 0,040 & $* *$ & $*$ & & \\
\hline Maitovalkuainen/rehuvalk., g/g & 0,29 & 0,29 & 0,27 & 0,30 & 0,008 & & $*$ & $*$ & \\
\hline
\end{tabular}

о $\mathrm{P}<0.10 ; * \mathrm{P}<0.05 ; * * \mathrm{P}<0.01 ; * * * \mathrm{P}<0.001$.

${ }^{2} \mathrm{SEM}=$ keskiarvon keskivirhe. 